\title{
A Childs' Right to Family Life when Placed in Public Care; an Analysis of Whether Current Norwegian Practice is in Systematic Contradiction to Human Rights
}

\author{
Tina Gerdts-Andresen \\ Assistant professor, Faculty of health and welfare, Østfold University \\ College, Østfold, Norway \\ tina.gerdts-andresen@hiof.no
}

\begin{abstract}
Based on both ECHR and CRC being incorporated into Norwegian law and underpinning the Child Welfare Act, this study aimed to clarify whether the current Norwegian practice is in systematic contradiction to human rights. The article is based on 94 Norwegian care orders comprising 117 children from newborn to 16 years old and analysis whether the child and parents' right to contact are safeguarded in the care orders. Contradictions and dilemmas between Conventional rights and Norwegian practice are addressed. The article's contribution presents analytical results, which describe the County Social Welfare Boards' practice when issuing care orders. The result reinforces the suspicion that current Norwegian practice may be in systematic contradiction to human rights.
\end{abstract}

\section{Keywords}

care orders - public care - child welfare - Family life - CRC art. 9 - contact rights

Since September 2019, the European Court of Human Rights (ECtHR) has found that Norway has violated Article 8 of the European Convention on 
Human Rights (ECHR) in nine different cases: Strand Lobben and others v. Norway (2019), A.S. v. Norway (2019), Abdi Ibrahim v. Norway (2019), K.O. and V.M. v. Norway (2019), Hernehult v. Norway (2020), Pedersen and others v. Norway (2020), R.O. v. Norway (2021), K.E. and A.K. v. Norway, and F.Z. v. Norway. All cases represent families where children were placed in public care, and where contact between parents and children was subjected to restrictions. In all cases, Norway was found to be in violation of the parents' and child's right to family life by the restrictions placed on contact between the child and its parents after the care order was issued.

ECtHR poses the question as to whether the Norwegian Child Welfare system gives up on reunification at too early a stage, by immediately defining the placement as long-term (K.O. and V.M. v. Norway, 2019). Further, the Court finds that the contact between the children and parents has been limited more strictly than what the Court decided to be in the best interest of the child and his/her parents (Strand Lobben v. Norway, 2019; A.S. v. Norway, 2019; Abdi Ibrahim v. Norway, 2019; Hernehult v. Norway, 2020; Pedersen and others v. Norway, 2020). The Court specifies the need to perform a genuine balancing exercise between the interests of the child and its biological family. Unless special reasons indicate otherwise, it will always be in a child's best interest to keep contact with his/her biological family (Strand Lobben v. Norway, 2019). While the Court refers to "the biological family" in Strand Lobben (2019), the Court, in previous cases (e.g. K. and T. v. Finland, 2001), has pointed out that the right to family life also applies to others with whom the child has "close personal ties".

Based on the six recent decisions of the ECtHR, it is reasonable to question whether the current Norwegian Child Welfare practice, regarding contact regulation between a child and its parents when a care order has been issued, is in systematic contradiction of Convention rights. Further analysis of the Norwegian practice is therefore needed, both to clarify whether there is a disparity between the Norwegian law and Convention rights, but also to clarify the extent of the contradiction.

\subsection{Mutual Right to Family Life and Contact}

The child and parents' mutual right to family life is protected under ECHR Article 8, a Convention that is incorporated in Norwegian law. The Convention provides a right to respect for one's 'private and family life, his home and his correspondence', subject to certain restrictions that are 'in accordance with law' and 'necessary in a democratic society'. The notion of "necessary" for the purposes of Article 8 means that the interference must correspond to a pressing social need and, in particular, must remain proportionate to the legitimate aim pursued. The term "necessary" in the context of Article 8 does not have 
the flexibility of expressions such as "useful", "reasonable", or "desirable" but implies the existence of a "pressing social need" for the interference (ECtHR, 2019). In Norway, Child Welfare Act of 17 July 1992 represents a law that regulates the restrictions to which the ECHR Article 8 (2) refers.

The general principles applicable to cases involving child welfare measures are well-established by the ECtHR (2019). Respect for family unity and for family reunification in the event of separation are inherent considerations in the right to respect for family life under Article 8. Accordingly, in the case of imposition of public care restricting family life, a positive duty is incumbent on the authorities to devise measures to facilitate family reunification as soon as reasonably feasible ( $K$. and T. v. Finland, 2001). Moreover, any measure implementing such temporary care should be consistent with the ultimate aim of reuniting the natural parents and the child.

A child's right to family life when placed in public care is closely related to the legal relationship between a child and his/her parents, as stated in both ECHR Article 8 and national Norwegian law. The main principal is that parents are responsible for their own children, and children have the right to live with their parents throughout childhood, and that this is in the child's best interest. As the ECtHR has highlighted in several cases, the best interests of the child indicate, on the one hand, that the child's ties with his/her family must be maintained, except in cases where the family has proved particularly unfit, since severing those ties means cutting a child off from his/her roots. It follows that family ties may only be severed in very exceptional circumstances and that everything must be done to preserve personal relations and, if and when appropriate, to "rebuild" the family (e.g. Strand-Lobben v. Norway, 2019). A child's right to know their parents and receive care from them is ratified in Norwegian law from, e.g., the Convention on the Rights of the Child (CRC) Article 7: '... to know and be cared for by his or her parents'. Several of the provisions in the CRC require states to respect and protect the relationship between children and their parents (e.g. Arts. 3(2), 8(1), 9, 10, 14(2), 16, 18, 19, 27 and $4 \mathrm{O}(2)$ ), and Norway has incorporated the CRC as Norwegian law. In the event of conflict, the CRC takes precedence over other Norwegian legislation. This provides the CRC a unique position as a common basis for working with and for children across countries. It is not explicitly stated that parents and children have an unconditional right to be together. However, the right to family life is protected by the Norwegian Constitution of 17 May 1814, sections 102 and 104 in which provisions are to be interpreted and applied in the light of their international law models. This includes a variety of Conventions and the case law from the ECtHR. The rights guaranteed by section 104 are inspired by the CRC and the wording of CRC has been used as guidance when drafting several parts of the constitutional provision. Practice from the Committee on 
the Rights of the Children (CtRC) will therefore be of high relevance when interpreting a child's right to family life after having been placed in public care in Norway (Søvig, 2019).

Another guiding principle of the ECtHR is that a care order should be regarded as a temporary measure, to be discontinued as soon as circumstances permit, and that any measures implementing temporary care should be consistent with the ultimate aim of reuniting the natural parents and the child $(K$. and T. v. Finland, 2001). For the parent-child relationship, this is supplemented by CRC Article 9(3), which states that children who are separated from one or both parents have the right 'to maintain personal relations and direct contact with both parents on a regular basis'. According to ECHR Article 8, family ties may only be severed in 'very exceptional circumstances'. Where the respective interest of a child and those of the parents come into conflict, Article 8 requires that the domestic authorities should strike a fair balance between those interests and that, in the balancing process, particular importance should be attached to the best interest of the child (Hernehult v. Norway, 2020). Contact may only be restricted if it is 'contrary to the child's best interest'. In General Comment No. 14 (2013), the CtRC mentions the following as elements 'to be taken into account when assessing the child's best interests'; (a) the child's views, (b) the child's identity, (c) preservation of the family environment and maintaining relations, (d) care, protection and safety of the child, (e) situation of vulnerability, (f) the child's right to health, and (g) the child's right to education. In the best-interests assessment, the CtRC points out the importance of considering that the capacities of the child will evolve. Decision-makers should therefore consider measures that can be revised or adjusted accordingly, instead of making definitive and irreversible decisions. To do this, they should not only assess the physical, emotional, educational and other needs at the specific moment of the decision but should also consider the possible scenarios of the child's development, and analyse them in the short and long term. In this context, decisions should assess continuity and stability of the child's present and future situation.

\subsection{Certain Restrictions that are 'in Accordance with' Law}

The ECtHR (2019) has repeatedly affirmed that any interference by a public authority with an individual's right to respect for private life and correspondence must be in compliance with the law, cf. ECHR Art. 8(2). The national law must be clear, foreseeable and adequately accessible (Silver and Others $v$. the United Kingdom). With regard to foreseeability, the phrase, "in accordance with the law" implies that domestic law must be sufficiently foreseeable in its terms to give individuals an adequate indication as to the circumstances in which, and the conditions on which, the authorities are entitled to resort 
to measures affecting their rights under the ECHR (ECtHR, 2019). In Norway, Child Welfare Act section 4-12, letters a-d, describe situations in which a care order may be issued. A care order may be issued if there are 'serious deficiencies in the day-to-day care received by the child' or 'serious deficiencies in terms of the personal contact and security needed by the child of his or her age and development'. A care order may also be issued if the parents 'fail to ensure that a child who is ill, disabled or in special need of assistance receives the treatment and training required', if the child has been 'mistreated or subjected to other serious abuse at home', or if it is 'highly probable that the child's health or development may be seriously harmed because the parents are unable to take adequate responsibility for the child'. However, an order may only be made when necessary based on the child's current situation. Hence, such an order may not be made if satisfactory conditions can be created for the child by measures of assistance, cf. section 4-12(2). The ECtHR has found that this provision complies with the ECHR Article 8 requirement of 'very exceptional circumstances'.

In Norway, the County Social Welfare Board issues care orders. These orders may be challenged before the general courts, at three instance levels and with the Supreme Court as the superior court. The County Social Welfare Board, however, is the only decision-making authority that is guaranteed to handle all cases where children are placed in public care by force (Høyland, 2003).

Unless otherwise provided, children and parents are also entitled to have contact with each other after a care order has been issued. However, the Child Welfare Act, section 4-19 (2), allows the County Social Welfare Board to determine the extent of contact. If necessary, for the sake of the child, they may decide that there should be no contact. The County Social Welfare Board may also decide that the parents should not be entitled to know the child's whereabouts. The right to have contact with each other is not only a right of the child, but also a right of the parents. When it comes to the question of how extensive the contact should be, neither the Child Welfare Act nor the Norwegian court judgments provide specific guidance. The ECtHR (2019) has seen the need to clarify the terms that follow from ECHR Article 8, which applies as applicable law in Norway. The mutual enjoyment by parent and child of each other's company constitutes a fundamental element of family life within the meaning of Article 8 of the Convention, and domestic measures hindering such enjoyment constitute any interference with the right protected by the Article. There is, however, a broad consensus that in all decisions relating to children, the best interests of the child must be the paramount concern. The child's best interests, depending on their nature and seriousness, may override those of the parents. The parents' interests, especially in having regular contact with their child, nevertheless remain a factor when balancing the various interests at stake. 
There are several Norwegian Supreme Court judgments concerning the determination of contact rights under the Child Welfare Act. The judgments emphasise, however, that the purpose and duration of the public care decision will be of significant importance, and where it distinguishes the extent of contact rights to be established in short-term and long-term placements (Rt. 2012:1832; HR-2O2O-662-S). This shall apply, despite the fact that the ECtHR states an ultimate aim of reuniting the natural parents and the child, as soon as reasonably feasible, with no need for further duration determination (e.g. Strand Lobben v. Norway, 2019). According to the Norwegian Supreme Court, if a placement is defined as 'short-term', the parents should be granted more frequent contact so as to facilitate the return of the child. Where the placement is defined as 'long-term', the contact should be less frequent so as to give the child the stability and continuity required to establish a good relationship with the new caregivers. The purpose of establishing contact rights in such cases is to allow the child to gain a cognitive and intellectual understanding of whom his or her biological parents are, not to create or maintain an emotional connection. Relevant aspects when deciding restrictions of the children and parents' right to have contact will be the child's age, the child's characteristics, the child or parent's special needs, the child's reactions related to contact, as well as the collaborative climate in the case (Ministry of Children, Gender Equality and Inclusion, 2012; Haugli, 2000). According to both Norwegian law and the ECHR, any care order placement is considered a 'temporary measure'. However, based on the Norwegian practice, ECtHR has questioned whether cases defined as 'long-term' prevent reunification of children and their families due to strict limitations of their contact rights. The Court emphasises that family reunification cannot normally be expected to be sufficiently supported if there are intervals of weeks, or even as much as months between each contact session (K.O and V.Mv. Norway, 2019).

\subsection{Aim}

Based on the incorporation of both the ECHR and CRC into Norwegian law, thereby underpinning the Norwegian Child Welfare Act, the aim of this study is to clarify whether current Norwegian practice is in systematic contradiction to human rights. The question that arises is whether the six cases where ECtHR found Norway in violation of the rights to family life are to be understood as single cases, or if there is an ongoing systematic contradiction between the Conventional rights and Norwegian Child Welfare practice. 
$2 \quad$ Method

\subsection{Procedure and Data Material}

This study aims to examine the County Social Welfare Boards' practice, as the boards are both involved in issuing all care orders and indicators that show through their application of the law what is understood as current law. The data were derived from the public register Lovdata (www.lovdata.no), which provides access to a collection of online legal resources, including anonymous decisions from the County Social Welfare Board. The Norwegian Child Welfare Act has undergone several revisions and content changes in recent years. The last revision is still ongoing, but with several changes implemented from 1 July 2018. The selected search period was therefore set from 1 July 2018 to 31 December 2019, to ensure that the decisions included in this study are based on current Norwegian law.

The initial search provided a total of 358 County Social Welfare Board decisions as potentially relevant decisions. All decisions were screened based on abstract and conclusion to identify which decisions concerned placement of children in public care, cf. section 4-12 of the Child Welfare Act. Other decisions concerned, e.g., reversal requirements, questions on change in contact between a child and its parents, temporary decisions in emergencies, adoption and decisions that order the start of intervention while children are living with their parents. Only decisions that concerned 'placing children in public care', cf. section 4-12 a-d, were of interest in accordance with the aim of this study. This amounted to a total of 108 decisions. Of the 108 decisions, there were 14 decisions where the children were not placed in public care. These 14 decisions do not contain regulation on contact rights between the child and his/ her parents and were therefore excluded from further analysis. 94 decisions were included in the study for further analysis; 40 decisions made in the period 1 July 2018 to 31 December 2018 and 54 decisions made in the period 1 January 2019 to 31 December 2019.

Included decisions comprise a total of 117 children, $5^{8}$ girls and 59 boys, within 94 families. In 54 per cent of the decisions, the mother has sole custody. In 28 per cent of the decisions both parents are responsible for the daily care of the child, while in 18 per cent of the decisions, the father has sole custody. The children range in age from newborn to 16 years, see Table 1.

\subsection{Data Extraction}

Document analysis is a systematic procedure for reviewing or evaluating documents. Like other analytical methods in qualitative research, document analysis requires that data be extracted and interpreted in order to elicit meaning, 


2018
2019 Total

Amount Pct. Amount Pct. Amount Pct.

Issued care orders

Included decisions

40

43

54

57

94

100

Care responsibility

Both parents

Mother with sole custody

12

13

$$
14
$$

$$
15
$$

26

28

Father with sole custody

$18 \quad 19$

33

35

51

54

10

11

7

7

18

Affected Children

Total
-Girls
-Boys
o-2 years
3-6 years
7-11 years
12-14 years
15-18 years

$\begin{array}{rrrrrr}51 & 44 & 66 & 56 & 117 & 100 \\ 26 & 22 & 32 & 28 & 58 & 50 \\ 25 & 22 & 33 & 28 & 58 & 50 \\ 10 & 9 & 12 & 11 & 22 & 20 \\ 14 & 12 & 11 & 9 & 25 & 21 \\ 15 & 13 & 23 & 20 & 38 & 33 \\ 5 & 4 & 11 & 9 & 16 & 13 \\ 7 & 6 & 9 & 7 & 16 & 13\end{array}$

gain understanding and develop empirical knowledge (Corbin and Strauss, 2008; Rapley, 2007). In order to decide whether current Norwegian practice is in systematic contradiction to human rights, it was therefore necessary to extract and interpret information from the care orders regarding restriction on the parents' and child's right to contact and family life.

Data were extracted from the included care orders using a predetermined form and any absent or unclear information was marked next to the relevant item. To be able to interpret whether a restriction violates human rights, information on both the child and parents' functioning and professional judgment are of interest. The extracted information included (1) decision date, (2) which section the care order was issued by and justifications for the care order, (3) daily care responsibility, (4) description of the child, (5) child's age and gender, (6) ethnicity, (7) the expected duration of the care decision, (8) decision on contact possibilities, (9 and 10) restrictions on contact, and (11) care base within or outside the family. By using document analysis in combination with a mean of triangulation, it is attempted to provide confluence of evidence that breeds credibility (Bowen, 20o9). By examining information collected through all included decisions, it will be possible to corroborate findings across 
decisions and thus reduce the impact of potential biases that may exist in a single case study.

Correlation analysis was carried out to explore relationships between the child and parents' regulation in contact, the child's age, the child's characteristics, the child or parent's special needs, the child's reactions related to contact, and the collaborative climate in the case. Correlation provides an indication of whether there is a relationship among variables. It does not, however, indicate that one variable causes the other. The possibility of a third variable potentially influencing both of the observed variables was considered (Frey et al., 1999).

\section{$3 \quad$ Results}

\subsection{Justifications of the Care Orders}

All 94 care orders were issued in accordance with Norwegian Child Welfare Act section 4-12 (a) in the period from 1 July 2018 to $3_{1}^{1}$ December 2019, and where it was both "necessary" and in the best interest of the child to be placed under public care. All care orders are purported to be in line with ECHR Article 8.

The County Social Welfare Board issued 21 of the 94 care orders due to '... serious deficiencies in the day-to-day care received by the child'; neglected children, e.g. repeated relocations and school changes, children without adult supervision, or lack of food, clothing and necessary equipment over a longer period of time. In all cases, repeated, differently composed and varied interventions (e.g. financial support, guidance, practical assistance, treatment for possible underlying problems, various activity offers for the child outside the home) were implemented without having the necessary changing effect on the child's living conditions. The care conditions were found to affect the child's quality of life, and for some of the children, it also adversely affected the child's development.

In a total of 65 of the 94 care orders, the Board found '... serious deficiencies in terms of the personal contact and security needed by a child of his or her age and development'; e.g. violence, danger of forced marriage, mental illness in parents over a longer period of time and without improvement in sight, substance abuse over a longer period of time and without sobriety in sight, parental conflict. In families where violence was a factor, the violence was considered as a result of parents' mental illness, drug abuse or lack of parenting skills, and not as '...serious abuse' cf. section 4-12 (c):

The Board finds that (name of child) has been subjected to violence from (parent) but this is not the main issue within the child's care situation today. 
Of the 65 care orders, the Board referred in 21 care orders, to parents' lack of understanding the child's emotions, lack of providing the child with necessary regulatory help or difficulty in helping the child to understand how to relate and act socially. In addition, the Board emphasised cultural disagreements between the child and his/her parents that prevented the parents from providing the child with necessary developmental support, in six of the care orders. In most cases, repeated, differently composed and varied interventions (e.g. guidance, practical assistance, treatment for possible underlying problems, various activity offers for the child outside the home, voluntary temporary foster care, parent - child centre, and various interventions to control the home environment) had been implemented without having the necessary changing effect on the child's living conditions.

The remaining eight care orders were issued due to both '... serious deficiencies in the day-to-day care received by the child' and '...serious deficiencies in terms of the personal contact and security needed by a child of his or her age and development'; e.g. both practical and emotional failure of care, neglect and mental illness, instability and mental illness, physical and mental illness, or neglect and substance abuse.

\subsection{Expected Duration of the Care Decisions}

The Norwegian Supreme Court judgments (Rt. 2012:1832; Rt. 2015:467; HR-202O-662-S) emphasise that the purpose and duration of the public care decision shall be of significant importance when considering restrictions on contact between a child and his/her parents. The County Social Welfare Board therefore distinguishes between short-term and long-term placements when care orders are issued. This distinction is not stated in ECHR Article 8, and ECtHR states that the ultimate goal is to 'facilitate family reunification as soon as reasonably feasible' (K.O. and V.M. v. Norway, 2019; Strand Lobben v. Norway, 2019).

Of the 94 care orders that were investigated in this study, 88 of the care orders, 94 per cent, were defined as long-term placements. Six of the care orders were defined as short-term placements, while two care orders were defined as having an unclear duration.

\subsubsection{Long-Term Placements}

The County Social Welfare Board's justification when defining 88 of the care orders as long-term placements refers to one or more of the following: (1) the parents' own problems, (2) the child's age, combined with expected treatment perspective for the parents' own problems, (3) the child's need for adult support exceeds the parent's capacity both now and in near future, or (4) that 
expectations are limited in terms of change in the parent's care skills in the (near) future.

Out of the 88 care orders, 11 care orders issued pertained to children under the age of one; three of the care orders concerned parents with cognitive impairment, and where various supportive interventions had not led to necessary changes. Three care orders concerned immature parents, who had demonstrated difficulty with putting the child's needs before their own desires, and by their behaviour showing lack of emotional care for the child. Two care orders concerned parents with ongoing substance abuse, while two care orders concerned parents with mental health problems. One care order concerned parents with both substance abuse and mental health issues.

Moreover, 11 of the 88 care orders were issued for children between the age of one and three; four care orders concerned parents with mental health issues, two concerned neglect, one concerned substance abuse, two concerned lack in emotional care for the child, and two concerned a combination of neglect and mental health issues.

A total of 18 of the 88 care orders were issued for children from the age of three to six; five care orders concerned parents with mental health issues, two concerned neglect, one concerned substance abuse, and two concerned lack in emotional care for the child. Two care orders concerned a combination of substance abuse and violence, two concerned a combination of substance abuse and mental health issues, and four concerned a combination of practical and emotional failure of care.

Of the 88 care orders, 59 were issued for children between the age of 7 and 16; 7 care orders concerned parents with mental health issues, 15 concerned neglect, 4 concerned various forms of violence, while 3 concerned parental substance abuse. Fourteen care orders concerned lack in emotional care for the child; 5 concerned the child's need for adult support that exceeded the parent's capacity, while six concerned cultural differences between the child and its parents. Two care orders concerned a combination of substance abuse and mental health issues, and three concerned a combination of practical and emotional failure of care.

Based on ECHR Article 8, there is reason to question whether the Board's definition on expected duration of a care order, prior to the placement, prevents follow-up according to ECHR standards. In order for this to be in line with the ECHR, the authorities must take measures to facilitate family reunification (K.O. and V.M. v. Norway, 2019; Strand Lobben v. Norway, 2019). It is only under 'exceptional circumstances", e.g. if the parents are 'particularly unfit', or reunification may 'harm the child's health and development', or 'when considerable 
period of time has passed' since the care order was issued, that the duty to reunify the family does not apply.

\subsubsection{Short-Term Placements}

The County Social Welfare Board's justification when defining six of the care orders as short-term placements refers to either (1) the parents' own problems, (2) the child's need for adult support exceeds the parent's capacity at the time of issue, or (3) neglect as a result of the parents' health issues.

One care order concerned a mother with mental health issues and a 7 sevenyear-old girl; another, a father with physical health issues and a ten-year-old boy. The County Social Welfare Board emphasised that it could not be ruled out that the parent's health issues were related to stress. Further interventions were needed before defining the duration of the placement. Two other care orders concerned families where the child's need for adult support exceeded the parent's capacity. The children's ages were 11,13 and 14. The goal was stated in the care orders: to reunite the children with their parents as soon as it was justifiable.

Another care order concerned parental conflict and an 11-year-old girl. The County Social Welfare Board considered the mother unfit to provide daily care for the girl. The mother was also unwilling to let the father have daily care for the girl. By giving the girl protection in public care, the Board concluded it was possible for the parents to solve their conflicts so that in the long term, the girl could be transferred to the father's care.

The last care order involving short-term placement concerned a mother with substance abuse and a nine-year-old girl. The mother had had many years of substance abuse in the past, at times heavy drug abuse. However, she managed to become sober, and it could therefore not be ruled out that she could potentially manage to become sober again. The attachment between the girl and mother was described as good.

Focusing on the placement as 'short-term' is in line with the ECtHR guiding principle that all care orders should be regarded as a temporary measure, to be discontinued as soon as circumstances permit (e.g. Strand-Lobben v. Norway, 2019). It is astonishing, however, that only six per cent of the included care orders in this study were defined as 'short-term' placements. This provides grounds for questioning whether the Board's definition of expected duration of a placement are in line with the child and families' Conventional rights.

\subsubsection{Undefined Duration}

Out of 94 care orders, County Social Welfare Board found two care orders of undefined duration. One case concerned a 14-year-old girl who lived with her 
mother. Her parents were divorced, with a parental conflict ongoing over several years. The County Social Welfare Board found that there were difficulties in the relationship between the child and her parents causing her to behave antagonistically towards them. At the same time, there was a deep concern for the girl's mental health. Public care was therefore considered necessary at the time of the care order was issued, the purpose of the placement being to give the girl time to re-establish a relationship of mutual trust with her parents. The time perspective of the process could not be determined, nor the possibility that she might need public care until the age of 18 .

The other case also concerned a 14-year-old girl living with both her parents. The girl had dropped out of school and was antagonistic towards her parents. The County Social Welfare Board found that there was no need for a distinction between a short-term and long-term placement in this case. They emphasised that the girl had lived with her parents all her life and was attached to them. Due to the girl's age, they found it likely that the parents would play a central role in her life both during and after the placement.

In accordance with ECHR Article 8, the Board's focus in these cases is not on defining the duration of the care order, but on safeguarding the child-parent relationship. Although separation is found to be both 'necessary' and 'in the best interest of the child', the ultimate goal is to 'rebuild' the family. However, there is reason to question why only 2 out of 94 care cases highlight this as a main focus, particularly when this focus is in line with the child and families' Convention rights.

\subsection{Restriction on Contact}

In accordance with the Norwegian Child Welfare Act section 4-19, The County Social Welfare Board determined the extent of contact in all 94 care orders, claiming that the extent of contact which is written in the care order is to be understood as a minimum of contact between the child and its parents. The Child Welfare Service has the authority to increase the contact in line with what they consider to be in the best interest for the child. When the Board goes about setting restrictions on contact rights between a child and his/her parents, ECHR Article 8 requires a fair balance between both child and parents' right to contact. As contact may only be restricted if it is 'contrary to the child's best interest', any restrictions need to be clearly justified in the care order.

\subsubsection{Long-Term Placements}

A review of the 88 long-term placement decisions, regarding the contact rights of 107 children, show a range of differences in contact from 'no contact' to 'one afternoon per week, every other weekend and 4 weeks holiday 
per year'. Moreover, despite a relatively wide range of contact restrictions, the Board found it necessary in 46per cent of the cases to restrict the contact rights between the child and both parents to a total of two to six meetings per year, with a median of five. The duration of the meetings varies from one to six hours per meeting with a median of two. In 21 per cent of the care orders, the children could meet the parents from seven to nine times per year, with a median of eight. The duration of the meetings varies from one to six hours per meeting with a median of three. In 13 per cent of the care orders, the children could meet the parents 10 or 12 times per year, with a variance of one hour to six hours per meeting and a median of three.

In 9 per cent of the 88 care orders, the child was allowed overnight visitation. Overnight visitation ranged from one night to five nights per meeting, 4 to 24 times per year with a median of ten. The remaining 10 per cent of the care orders restricted contact as follow: no visitation rights, 16 meetings per year 2-4 hours per meeting, 18 meetings per year 5 hours per meeting, or 24 meetings per year as day visits.

In 61 per cent of the 88 care orders, Child Welfare Services would be allowed to supervise the visits; 15 per cent as regards children under the age of one, 14 per cent as regards children between one to three years old, 27 per cent as

\section{TABLE 2 Visitation rights in long-term placements}

$3^{\circ}$

25

20

15

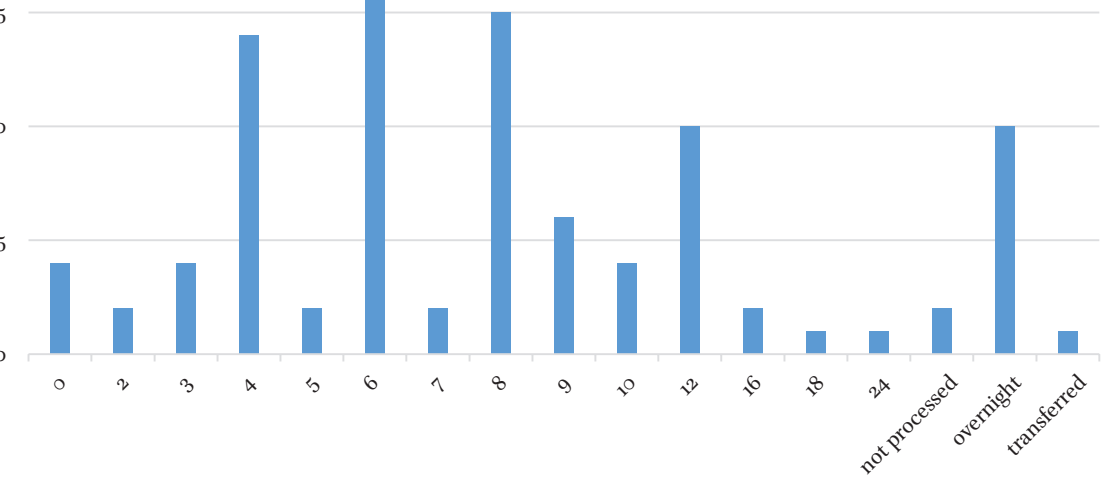


regards children between the ages of three to six 6 , and 44 per cent as regards children between the ages of 7 to 16 years. In the care orders where the child's age was from 3 to 16 ( 71 per cent), most care orders justified the restriction with prevention 'just in case', for example:

... It has been stated that, as of today, it does not appear necessary [i.e. supervision], but at the same time it seems very uncertain how the child will react to the care order. It is therefore important that Child Welfare Service has the opportunity ...

...Nevertheless, it is important that the supervision is adapted to the situation and should not be more comprehensive than what is considered necessary.

... (Parent) has no objection to supervision ...

...the Board considers it positive if [parent] receives guidance on structure during visitations.

Based on the ECHR Article 8 notion of "necessary", it is reasonable to question whether the Board has developed a practice that is in contradiction to the child's and families' Convention rights. By establishing restrictions 'just in case', the Boards' justification lack legal grounding in a 'pressing social need'.

Telephone and social media contact was restricted in 10 per cent of the care orders, with children ranging in age from 3 to 14 . The restriction is justified by citing the child's need to become established in new surroundings, for example:

... electronic contact between [parent] and [child] must be limited to twice a month, as [child] needs tranquility in the foster home.

... the Board believes that it would be in the best interest of the child not to be influenced by [parents] on a daily basis. There shall therefore not be any electronic contact between [parent] and [child].

As the quotes exemplify, the Board does not justify the necessity of restricting telephone and social media contact based on 'pressing social need', as ECHR Article 8 requires. As the care orders are presented in written form, it is therefore reasonable to question whether the Board's practice is in line with ECHR standards. 
In several of the care orders, the restriction applied only to the parents, claiming the child had free access to contact their parents at their own discretion. None of the care orders, however, highlights a 'pressing social need' for the interference, claiming the regulation is in 'the best interest of the child' without weighing the different elements according to CRC Article 9(3) (CtRC, 2013). Lack of justification gives grounds to question whether the Board's regulation is in contradiction of the parents' Convention rights.

In 6 per cent of care orders, the Board found it necessary to restrict the contact rights to the degree that the parents were not allowed to know the child's whereabouts. According to ECHR Article 8, family ties may only be severed in 'very exceptional circumstances'. Based on what the Board has written, it is unclear whether the justification of the contact regulation was 'necessary' due to 'very exceptional circumstances', and it is therefore not possible to consider if the regulations are proportionate to the Conventional rights. However, lack of justification in itself will be a contravention of both Norwegian law and the Convention rights.

Overall findings show that the children are maladjusted in 56 per cent of the 88 care orders at the time of the issue. Analysis shows no correlation between any of the forms of contact regulation and the child's age, the child's characteristics, the child or parent's special needs, the child's reactions related to contact, or the collaborative climate in the case, within the care orders defined as long-term placements or in relation to short-term or undefined duration placements.

\subsubsection{Short-Term Placements}

The County Social Welfare Board considered 7 of the 94 care orders most likely to be short-term placements. These care orders involve 7 children between the age of 7 to 16 , of whom 5 are described as having maladjustments at the time of the issuance of the care order.

A review of the seven decisions shows a variance in contact from 'four hours eight times a year' to 'full day visit thirty-two times a year'. None of the care orders allowed overnight visitation. In three of the care decisions, the Board found it necessary to restrict the contact rights between the child and parents to 24 meetings per year, with a variation of $2-6$ hours per meeting with a median at 4. In two of the care orders, the children could meet the parents eight times per year, with a range of two hours to 'full day visit' per meeting. One of the care orders allowed the child to meet the parents 12 times per year, with a variance of $2-4$ hours per meeting. The last of the seven short-term placement care orders allowed the child to meet the parents 32 times per year, $3-5$ hours per meeting. 
Although the care orders appear to be in line with the child and parents' Conventional rights, as the placement is defined as 'short-term placement', the Board's regulation on contact rights lack justification based on factual conditions that make it 'necessary' to regulate contact rights in the manner decided. Lack of justification tends to offer support for the notion that the Board's decision is in contradiction to the child and parents Conventional rights (e.g. Strand Lobben v. Norway, 2019).

In 57 per cent of the care orders, the Child Welfare Services would be allowed to supervise the visits. This amounts to adding an extra restriction on the contact regulation cf. ECHR Article 8. Most care orders where supervision was allowed justifies the preventive restriction with the proviso, 'just in case'. Telephone and social media contact were restricted in one of the care orders involving an 11-year-old girl. The restriction was justified in the child's need to become established in new surroundings and regulated only the parents' contact rights. The Board's justification highlights a discrepancy between the terms of ECHR Article 8, which allows the aforementioned contact regulation, and the Board's practice, leading to the conclusion that the Board's contact regulation is more restrictive than that which is allowed by Convention rights.

Overall findings show no correlation between contact regulation and the child's age, the child's characteristics, the child or parent's special needs, the child's reactions related to contact, or the collaborative climate in the case, neither among the care orders defined as short-term placements nor among to long-time or undefined duration placements.

\subsubsection{Undefined Duration}

Among 94 care orders, the County Social Welfare Board found two orders of undefined duration. A review of the two decisions showed contact variance from 18 meetings per year $4^{-6}$ hours per meeting in one decision, to 10 meetings per year 2-4 hours per meeting in the other decision. However, as the care orders lack justification as to why the specific contact variance was decided in each case, it is difficult to assess whether the contact regulation was 'necessary' and thereby in line with the Convention rights.

One of the care orders allowed the Child Welfare services to supervise the visits and justifies the restriction with the preventive proviso, "just in case". Telephone and social media contact were restricted in the same care order, involving a 14-year-old girl. The restriction is justified by the child's need to become established in new surroundings and regulated only the parents' contact rights. The child in both care orders is described as maladjusted. By adding this restriction without a justification in terms of 'necessary' due to 'very 
exceptional circumstances', cf. ECHR Article 8, the validity of the decision may be called into question.

Overall findings show no correlation between contact regulation and the child's age, the child's characteristics, the child or parent's special needs, the child's reactions related to contact, or the collaborative climate in the case, neither among the care orders with undefined duration of placements nor among long- and short-time placements.

\section{4 \\ Discussion}

Based on 94 County Social Welfare Board decisions, this study investigates whether the current Norwegian practice is in systematic contradiction to ECHR. The question that arises is if the six cases (K.O. and V.M. v. Norway, 2019; Strand Lobben v. Norway, 2019; A.S. v. Norway, 2019; Abdi Ibrahim v. Norway, 2019; Hernehult v. Norway, 2020; Pedersen and others v. Norway, 2020, R.O. v Norway, 2021; K.E and A.K. v. Norway, 2021; F.Z. v. Norway, 2021) where ECtHR found Norway in violation of the rights to family life are to be understood as single cases, or if there is an ongoing systematic contradiction between the Convention rights and Norwegian Child Welfare practice. With an overall finding of no correlation between any of the forms of contact regulation and the child's age, the child's characteristics, the child or parent's special needs, the child's reactions related to contact, or the collaborative climate in the case, there is a need for further discussion. First, there is an issue about whether defining the care orders as long- and short-term placements prevents the Child Welfare System from working towards a reunification. Second, there is an issue about whether the restriction on contact as shown in these care orders is in line with the child and parent's right to maintain contact, c.f. ECHR Article 8.

\subsection{The Right to be Reunited}

Family unity and family reunification in the event of separation are inherent considerations in the right to respect for family life, c.f. ECHR Article 8. As stated in the Child Welfare Act section 4-16, the Child Welfare Service shall arrange for the parents to regain care of the child when consideration of the child does not contradict it. A question that arises from the findings is whether it seems reasonable that 94 per cent of all care cases contradict the child's right to be reunited with their parents. By defining whether a placement is expected to be short- or long-term, the County Social Welfare Board sets the limits for the child and parent's future possibility to be reunited. Even though findings 
in this study show limited differences in contact regulations in cases defined as short- or long-termed placements, the Board's definition affects how Child Welfare Services follow up the family after the care order is issued. According to the preparatory work of section 4-16, the purpose of the Child Welfare Service's follow-up of the parents will have to be based on the County Social Welfare Board's decision (Ministry of Children and Family Affairs, 2005). When the Board defines the placement as long-term, this indicates that reversal is not realistic. The content of follow-up should then consist of, e.g. guidance to facilitate contact with the child.

The consequence of the Board considering the placement being long-term is that the Child Welfare Services will not seriously pursue the possibility of reunification of the family. In some cases, this may turn out to be in the best interests of the child. However, it is necessary for the Board to demonstrate why the ultimate aim of reunification is not compatible with the interest of that specific child in each case, individually. The majority of care orders are not clear on this, using general terms as justification. The child's age, the child's characteristics, and the child or parent's special needs, child's reactions related to contact (and possible reactions related to restriction on contact), and the collaborative climate in the case are all important elements of this decision (Haugli, 2000). By clearly defining what special needs the child has and assessing this against the parent's ability to meet the child's needs within a shorter or longer period of time (Sparta and Koocher, 2006), this tends to support rather than reject their right to work towards reunification.

In some cases, an assessment of parenting capability and parents' capacity to change will lead to the conclusion that sufficient change to reduce the likelihood of significant harm is not possible within the timeframe of the individual child. In these cases, permanent (long-term) placement will be in the best interests of the child. However, placement of a child in public care may influence both the child and the parents in unforeseen ways. By defining the parents' changing potential in advance, there is a risk that families are not offered interventions that could contribute toward the reunification of the child and parents. This, however, could easily be ensured by distinguishing the length of the placement after considering what effect the placement has proved to have had on both the child and parents, demonstrating that the ultimate goal after issuing the care order is to work towards reunification of the family. At this point, the child is already under public care, giving the parents and Child Welfare System time to work without worrying about whether the child is protected.

In order to carry out an accurate analysis when assessing parenting capability and capacity to change, there is a need to formulate a case conceptualisation (Holland, 2003), setting out the various internal and external factors that 
influence parents' ability to meet their children's needs (Brandon et al., 2008; 2009; 2012). Assessment of parental capacity to change should be undertaken as a dynamic process in which strengths and weaknesses are identified, targets set and agreed, effective interventions identified and implemented, and progress is monitored over a specific time period. Assessing parents' capacity to change should involve four elements. First, a cross-sectional assessment of parents' current functioning should be conducted. Second, targets of change derived from an assessment of current strengths and deficits in the family should be specified. Third, intervention with proven efficacy for the client group with a focus on achieving clearly specified targets for change should be implemented. Fourth, changes in parenting should be objectively measured (Harnett, 2007).

Although all 94 care orders have good documentation on the parents' current functioning and specification of targets of change, the care orders show a difference in the degree of documentation on how the interventions have been implemented in the family and the extent of the analysis of the interventions' effectiveness. Consequently, there is a lack of a clear description of the 'necessity' of a permanent placement. The Board states in 88 of the 94 care orders that 'no interventions' can contribute to the 'necessary change'. 'Long-term placement is therefore in the best interest of the child'. All 88 cases concern multi-problem families. It is therefore important to highlight how the effectiveness of the offered interventions are interpreted. In cases where parents are facing complex, multi-layered problems, an integrated package of support may be required, tailored to meet the needs of each member of the family (Dawe and Harnett, 2007).

Based on the 94 care orders included in this study, it is reasonable to question whether the Norwegian Child Welfare system gives up reunification at too early a stage, by immediately defining the placement as long-term, as the ECtHR questioned in K.O. and V.M. v. Norway (2019). Alternatively, it might be that the documentation must be made clearer to demonstrate that the care orders are in line with the Convention rights.

\subsection{A Child's Right to Maintain Contact}

The Norwegian Supreme Court judgments emphasise that the purpose and duration of the public care decision will be of substantial importance when considering restrictions of contact between a child and its parents. If a placement is defined as "short-term" the parents should be granted more frequent contact so as to facilitate the return of the child. Where the placement is defined as "long-term", the contact should be less frequent so as to give the child the stability and continuity required to establish a 
good relationship with the new caregivers. The purpose of establishing contact rights in such cases is to allow the child to gain a cognitive and intellectual understanding of whom his or her biological parents are, not to create or maintain an emotional connection. Significant aspects when deciding restriction of children and parents' right to have contact are the child's age, the child's characteristics, the child or parent's special needs, the child's reactions related to contact, as well as the collaborative climate in the case (Haugli, 2000). However, findings in this study show that there is no such distinction, neither between short-term and long-term placements, nor regarding correlation between contact regulation and the child's age, the child's characteristics, the child or parent's special needs, the child's reactions related to contact, or the collaborative climate in the case.

Except for four care orders, all care orders allow the child to be in contact with his or her parents in varying forms. Justifications for the restrictions related to contact rights between the child and their parents appear random, are expressed in standardised phrases, and are not based on the factual appraisal, neither in the individual case nor in terms of the expected duration. All restrictions on contact rights are addressed in Supreme Court judgments. In the judgment of 6 December 2012 (Rt. 2012:1832, 36), the Supreme Court stated that, 'a specific appraisal must be made in each case ...', and that the '... number of meetings that are beneficial to the child will necessarily vary from case to case', even though most Supreme Court judgments varied between three to six meetings per year. It is stated in the same judgment, 'that it is not possible to establish a fixed "tolerance limit"' on contact rights. Nevertheless, the Board refers to the 2012 judgment as a statement of "fixed tolerance limit" when justifying the restriction in contact, for example:

... Supreme Court has handled several cases regarding visitation rights, in most cases the number of yearly meetings in long-term placements has varied from 3 to 6 per year.

... Indicating that it will be a long-term placement. Supreme Court has in such cases set visitation rights between 3 to 6 times per year.

... the 3 to 6 yearly meetings that the Supreme Court refers to as a standard visitation right in cases of long-term placements.

... Child Welfare Service and the parents have agreed on 12 visitation rights per year. This is, however, more than what is common when determining contact rights where the placement is assumed to be long-lasting. 
The Board's standardised phrases for justification of limitation in contact rights often refer to '.... a child's need for stability and continuity required to establish a good relationship to the new caregivers' or '... the child's need for tranquillity in the foster home', without regard to whether the child already had an attachment with the new caregivers, the child's age, the child's characteristics, the child or parent's special needs, the child's reactions related to contact, or the collaborative climate in the case. It seems that the Board believes the only way to support children who are taken into public care in their establishment phase, is to limit the contact between the child and his/her parents. Only one of the 94 care orders discusses or assumes how contact between the child and its parents may contribute positively towards the child's adaption to his/her new surroundings. When a care order decision lacks justification concerning why it would be in 'that specific child's best interest' (cf. CRC Art. 9 (3)) to have 'that specific limitation' on contact rights to his or her parents, the issue is raised as to whether that specific restriction is in line with their right to family life as reflected in both Norwegian law and ECHR Article 8.

\subsubsection{Supervision and Restriction in Telephone and Social Media Contact}

Referring to Child Welfare Act section 4-19, the County Social Welfare Board has the authority to restrict contact between a child and his/her parents, for example, by allowing supervision during visitations and restriction of telephone and social media contact. However, special reasons have to be adduced for such stringent limitations to be placed on the child's and parents' right to have contact with one another (ECtHR, 2019; Ofstad and Skar, 2015), cf. both Norwegian law and Convention rights. Thus, when the Board justifies these restrictions, they refer to how the Supreme Court judgments interpret and practice such restrictions:

When looking at the Supreme Court judgments, it appears that the theoretical basis, based on the understanding of the system, does not hold as applicable law, as the Court interprets and practises the law. In fact, it seems that there is an access to impose supervision - just in case.

HAUGLI AND HAVIK, 2018:144

It seems that the Supreme Court grants access to prevent unwanted incidents 'just in case'. However, the notion of 'necessary' for these purposes means that the interference must correspond to a 'pressing social need' and, in particular, must remain proportionate to the legitimate aim pursued, including when it regards supervision and restriction on telephone and social media contact. The 
ECtHR (2019) is clear that the flexibility of such expressions as "useful", reasonable", or "desirable" does not apply to the exception stated in ECHR Article 8 (2) to restrict contact between a child and its parents. Neither does 'just in case'. The existence of a 'pressing social need' is required for the intervention (ECtHR, 2019). It is this 'pressing social need' for that specific child that needs to be visualised in the Board's care order. The Board's statement, 'that it would be in the best interest of the Child not to be influenced by [parents] on a daily basis', does not visualise any 'pressing' social need. For the regulation to be in line with the Conventional rights, the Board is obligated to highlight why it would be in the best interests of that specific child and how this need is 'pressing'.

Based on the material in this study, it appears that both Supreme Court judgments and recent legal literature (Haugli and Havik, 2018) support a practice that appears to violate the Convention rights of both parents and children, namely, through use of contact regulations in the form of granting access to supervision and restrictions on telephone and social media contact to prevent unwanted incidents 'just in case'.

\section{Limitations}

As this study is based on care orders issued by the County Social Welfare Board without access to the subdocuments, the evaluation of whether the care orders are in line with the child's right to family life is based on a review of the Board's written documentation. However, it cannot be ruled out that lacking documentation may result in a somewhat distorted analysis and conclusion. The analysis is limited to the care order documents, where the information contained in the care orders are viewed in the light of Norwegian law, the CVC and the ECHR.

In summary, the findings from this study argue that Norwegian Child Welfare practices are in systematic contradiction with the child and parent's Conventional rights. By defining care orders as short- or long-term placements, the County Social Welfare Board draws attention away from the ultimate goal of reunification. Justifications for the restrictions related to contact rights between the child and his/her parents appear random, both regarding the extent of visitation rights, need for supervision during visitation rights and regulation on contact by telephone and social media. Most decisions are couched in standardised phrases and not based on the factual appraisal in the individual case. In order to safeguard rights 
to family life after a care order is issued, there seems to be a need for adjustment in terms of how the Board utilises CRC Article 9 and ECHR Article 8 when defining restrictions on the child's right to 'personal relations and direct contact with

\section{Acknowledgements}

The author expresses her gratitude to Dr. Stefan Sütterlin (Østfold University Collage) for critical reflection and guidance in the analysis and writing process. I also thank Heidi Aarum Hansen (Østfold University Collage) for participation in the framework process, and Harald Gerdts-Andresen for conversations and emotional support.

\section{Ethics Approval}

The study was performed in accordance with the principles of the World Medical Association (Declaration of Helsinki).

\section{References}

Brandon, M., Bailey, S., Belderson, P., Gardner, R., Sidebotham, P., Dodsworth, J., Warren, C. and Black, J., "Understanding Serious Case Reviews and their Impact: A Biennial Analysis of Serious Case Reviews 2005-7”, Research Report DCSF-RR129 (London: Department for Children Schools and Families, 2009).

Brandon, M., Belderson, P., Warren, C., Howe, D., Gardner, R., Dodsworth, J. and Black, J., "Analysing Child Deaths and Serious Injury Through Abuse or Neglect; What Can We Learn. A Biennial Analysis of Serious Case Reviews 2003-2005", Research Report DCSF RR O23 (London: Department for Children, Schools and Families, 2008).

Brandon, M., Sidebotham, P., Bailey, S., Belderson, P., Hawley, C., Ellis, C. and Megson, M., "New Learning from Serious Case Reviews: A two year report for 2009-2011", Research Report DFE-RR226 (London: Department for Education, 2012).

Bowen, B., "Document Analysis as a Qualitative Research Method", Qualitative Research Journal $2009(9(2))$.

Committee on the Rights of the Children, General comment No. 14 on the right of the child to have his or her best interests taken as a primary consideration (Art. 3, para. 1) (2013).

Corbin, J. and Strauss, A., Basics of qualitative research: Techniques and procedures for developing grounded theory (3rd edn.) (Thousand Oaks, CA: Sage, 2008). 
Dawe, S. and Harnett, P. H., "Improving family functioning in methadone maintained families: results from a randomised controlled trial", Journal of Substance Abuse Treatment 2007, 32, 381-390.

European Court of Human Rights, Guide on Article 8 of the European Convention on Human Rights. Right to respect for private and family life, home and correspondence (Council of Europe, 2019).

Frey, L., Botan, C. and Kreps, G., Investigating communication: An introduction to research methods (2nd edn.) (Boston: Allyn \& Bacon, 1999).

Harnett, P.H., “A procedure for assessing parents' capacity for change in child protection cases", Children and Youth Services Review 2007 (29(9)), 1179-1188

Haugli, T., Samvcersrett i barnevernsaker (2nd edn.) (Oslo: Universitetsforlaget, 200o).

Haugli, T. and Havik, T., Samver i barnevernsaker. Psykologiske og juridiske vurderinger (Oslo: Universitetsforlaget, 2018).

Holland, S., "The assessment relationship: interactions between social workers and parents in child protection assessments", British Journal of Social Work 2003 (30), 149-163.

Høyland, J., "Saksbehandlingen i fylkesnemnda", I.S. Tjomsland (ed.), Barnevern og omsorgsovertakelse (Oslo: Kommuneforlaget, 2003).

Ministry of Children and Family Affairs, Om lov om endring I lov 17. juli $1992 \mathrm{nr} 100 \mathrm{om}$ barneverntjenester og lov 13. desember $1991 \mathrm{nr}$. 81 om sosiale tjenester (sosialtjenesteloven) m.v. (Ot.prp. 64 2004-05) (Regjeringen.no, 2005).

Ministry of Children, Gender Equality and Inclusion, Bedre beskyttelse av barns utvikling -Ekspertutvalgets utredning om det biologiske prinsipp i barnevernet (NOU 2012:5) (Regjeringen.no, 2012).

Ofstad, K. and Skar, R. Barnevernloven med kommentarer (Oslo: Gyldendal norsk forlag, 2015).

Rapley, T., Doing conversations, discourse and document analysis (London: Sage, 2007). Sparta, S.N. and Koocher, G.P., Forensic Mental Health Assessment of Children and Adolescents (Oxford: University Press, 2006).

Søvig, K.H., "Incorporating the Convention in Norwegian law", in Langford, M., Skivenes, M. and Søvig, K.H. (eds.), Children's Rights in Norway. An implementation paradox? (Oslo: Universitetsforlaget, 2019).

\section{Legal Decisions}

Abdi Ibrahim v. Norway, 17.12.2019, 15379/16.

A.S. v. Norway, 17.12.2019, 6o371/15.

Hernehult: F.Z. v. Norway, 01.07.2021, 64789/17.

Hernehult v. Norway, 10.03.2020, 14652/16.

K. and T. v. Finland, 12.07.2001, 25702/94.

K.O and V.M: K.E. and A.K. v. Norway, 01.07.2021, 57678/18 
K.O and V.M. v. Norway, 19.11.2019, 64808/16.

Pedersen and Others $v$. Norway, 10.03.2020, 39710/15.

Silver and Others: R.O. v. Norway, 01.07.2021, 49452/18

Silver and Others $v$. the United Kingdom, 25.03.1983, 5947/72; 6205/73; 7052/75; 7061/75; $7107 / 75 ; 7113 / 75 ; 7136 / 75$.

Strand Lobben and others v. Norway, 10.09.2019, 37283/13.

Rt-2012-1832.

Rt-2015-467. 